\title{
Pengaruh Ukuran Perusahaan, Leverage, Pengungkapan Lingkungan, dan Kinerja Lingkungan pada Nilai Perusahaan
}

\author{
Ni Gusti Putu Wirawati ${ }^{1}$ \\ Fakultas Ekonomi dan Bisnis \\ Universitas Udayana, Indonesia
}

\author{
I G.A.M. Asri Dwija Putri² \\ Fakultas Ekonomi dan Bisnis \\ Universitas Udayana, Indonesia
}

\section{Dewa Nyoman Badera ${ }^{3}$ Fakultas Ekonomi dan Bisnis Universitas Udayana, Indonesia \\ Surel : asri_dwija@unud.ac.id}

\section{ABSTRAK}

Penelitian ini bertujuan untuk memperoleh bukti empiris mengenai pengaruh ukuran perusahaan, leverage, pengungkapan lingkungan, dan kinerja lingkungan pada nilai perusahaan di Perusahaan Indeks LQ45 yang terdaftar di BEI periode 20142018. Metode penentuan sampel yang digunakan adalah menggunakan purposive sampling. Teknik analisis data menggunakan uji Regresi Linier Berganda. Hasil penelitian ini menunjukan bahwa ukuran perusahaan dan pengungkapan lingkungan berpengaruh negatif dan tidak signifikan pada nilai perusahaan. Hal ini berarti besar atau kecilnya perusahaan tidak mempengaruhi nilai perusahaan. Leverage dan kinerja lingkungan berpengaruh positif dan signifikan terhadap nilai perusahaan. Hal ini berarti bahwa semakin baik kinerja lingkungan yang dicapai oleh perusahaan maka semakin tinggi nilai perusahaan tersebut.

Kata Kunci: Ukuran Perusahaan; Leverage; Pengungkapan Lingkungan; Kinerja Lingkungan; Nilai Perusahaan.

The Effects of Company Size, Leverage, Environmental Disclosure, and Environmental Performance on Company Value

\begin{abstract}
This study aims to obtain empirical evidence regarding the influence of company size, leverage, environmental disclosure, and environmental performance on the value of the company in the LQ45 Index Companies listed on the Indonesia Stock Exchange in the 2014-2018 period. The sampling method used is purposive sampling. Data analysis techniques using the Multiple Linear Regression test. The results of this study indicate that company size and environmental disclosure have a negative and not significant effect on firm value. This means that the size of the company does not affect the value of the company. Leverage and environmental performance have a positive and significant effect on firm value. This means that the better the environmental performance achieved by the company, the higher the value of the company.
\end{abstract}

Keywords: Company Size; Leverage; Environmental Disclosure; Environmental Performance; The Value of The Company.



e-ISSN 2302-8556

Vol. 30 No. 9

Denpasar, September 2020 Hal. 2417-2427

DOI:

10.24843/EJA.2020.v30.i09.p19

PENGUTIPAN:

Wirawati, N. G. P., Putri, I G.

A. M. A. D., \& Badera, I D.

N. (2020). Pengaruh Ukuran

Perusahaan, Leverage, Pengungkapan Lingkungan, dan Kinerja Lingkungan pada Nilai Perusahaan. EJurnal Akuntansi, 30(9), 2417-

2427

RIWAYAT ARTIKEL: Artikel Masuk: 24 Juli 2020

Artikel Diterima: 27 September 2020

Artikel dapat diakses : https://ojs.unud.ac.id/index.php/Akuntansi/index 


\section{PENDAHULUAN}

Nilai perusahaan menjadi sangat penting karena dengan memaksimalkam nilai perusahaan berarti juga memaksimalkan kemakmuran bagi pemegang saham yang merupakan tujuan utama semua perusahaan (Damayanthi, 2019). Nilai perusahaan dapat menarik minat para investor untuk menanamkan modal pada perusahaan tersebut (Sabatini \& Sudana, 2019). Untuk dapat meningkatkan nilai perusahaan ada berbagai faktor yang dapat mempengaruhi yaitu salah satunya adalah isu lingkungan. Di Indonesia, kinerja lingkungan perusahaan dinilai dan dievaluasi melalui program yang dibuat oleh Kementerian Lingkungan Hidup yang disebut PROPER (Program Penilaian Peringkat Kinerja Perusahaan dalam Pengelolaan Lingkungan Hidup). Pada tahun 2018, tercatat ada 1872 perusahaan yang mengikuti PROPER. Berdasarkan data dari Wahana Lingkungan Hidup (Walih) ada 302 konflik lingkungan hidup dan Agraria sepanjang 2017.

Ukuran perusahaan dapat juga berpengaruh pada nilai perusahaan (Aulia \& Agustina, 2015) dan (Prameswari \& Yustrianthe, 2017). Ukuran perusahaan menggambarkan besar kecilnya suatu perusahaan yang dilihat dari total aset, jumlah penjualan, dan rata-rata total penjualan maupun asset (Adiatma \& Suryanawa, 2018) dan (Ahmadi \& Bouri, 2017). Selain ukuran perusahaan, leverage merupakan salah satu faktor yang perlu mendapat perhatian penting dalam nilai perusahaan (Kori \& Rasmini, 2017). Leverage adalah penggunaan asset dan sumber dana oleh perusahaan yang memiliki biaya tetap dengan maksud agar meningkatkan keuntungan pemegang saham. Perusahaan yang menggunakan leverage dengan tujuan agar keuntungan yang diperoleh lebih besar dari biaya tetap, sehingga pada akhirnya berpengaruh pada nilai perusahaan (Wijayanti et al., 2016).

Pengungkapan lingkungan menjadi faktor penting juga dalam meningkatkan nilai perusahaan. Informasi mengenai lingkungan tidak hanya diperlukan oleh stakeholders dan bondholders, namun masyarakat juga kini semakin peduli dengan pengungkapan informasi yang berkaitan dengan kelestarian lingkungan (Lu \& Wang, 2020). Masyarakat membutuhkan informasi mengenai sejauh mana perusahaan sudah melaksanakan aktivitas sosialnya sehingga hak masyarakat untuk hidup aman, tentram, dan kesejahteraan karyawan terpenuhi (Santoso et al., 2017).

Kinerja lingkungan juga berpengaruh pada nilai perusahaan, PROPER merupakan alat Kementerian Lingkungan Hidup untuk menilai kinerja lingkungan perusahaan-perusahaan yang ada di Indonesia dilakukan dengan sistem pemeringkatan dengan memebrikan warna sebagai tandanya (Singh et al., 2011). Berdasarkan hal tersebut, maka PROPER dikembangkan dengan beberapa prinsip dasar yaitu peserta PROPER bersifat selektif, yaitu ntuk industri yang menimbulkan dampak penting terhadap lingkungan dan peduli dengan citra atau reputasi.

Teori sinyal (signalling theory) pertama kali dikembangkan oleh Ross (1977). Teori sinyal menjelaskan bahwa laporan keuangan dan non keuangan yang baik merupakan sinyal atau tanda bahwa perusahaan juga telah beroperasi dengan baik. Teori sinyal menekankan bahwa perusahaan wajib mengungkapkan informasi kepada pihak eksternal untuk memperkecil asimetri 
informasi dan mengurangi ketidakpastian akan prospek perusahaan di masa depan (Yanti \& Budiasih, 2016)

Berdasarkan teori sinyal, kinerja ,ingkungan dan pengungkapan lingkungan memberikan informasi kepada investor tentang prospek return masa depan yang substansial. Hal tersebut merupakan sinyal berupa good news yang diberikan oleh pihak manajemen kepada publk bahwa perusahaan memiliki prospek bagus di masa depan dan memastikan terciptanya keberlanjutan pembangunan. Dengan kinerja lingkungan yang baik dan pengungkapan lingkungan tegas, perusahaan berharap dapat meningkatkan reputasi dan nilai perusahaan melalui peningkatan return saham.

Teori stakeholder adalah teori yang menggambarkan kepada pihak mana saja perusahaan bertanggung jawab (Freeman et al., 2010). Lindawati \& Puspita (2015) menyatakan bahwa tujuan utama dari teori stakeholder adalah untuk membantu manajemen perusahaan dalam meningkatkan penciptaan nilai sebagai dampak dari aktivitas-aktivitas yang dilakukan dan meminimalkan kerugian yang mungkin muncul bagi stakeholder.

Teori legitimasi dan stakeholder menjelaskan aktivitas dari perusahaan yang lebih besar akan lebih terlibat dan juga lebih memungkinkan untuk mengungkapkan lebih banyak informasi jika dibandingkan dengan perusahaan yang lebih kecil sehingga tuntutan dari masyarakat dan juga para pemangku kepentingan akan menjadi lebih besar. Ukuran perusahaan ditunjukkan melalui total aset, tingkat penjualan, maupun nilai pasar saham. He \& Luo (2018) menyatakan dalam penelitiannya bahwa perusahaan yang lebih besar akan mendapatkan tekanan yang lebih besar pula dari kalangan publik dan para stakeholder mempunyai ekspetasi yang tinggi. Hal tersebut membuat perusahaan terdorong untuk membangun citra atau image yang positif untuk memperoleh legitimasi dari publik maupun stakeholder perusahaan tersebut dengan cara melakukan pengungkapan sosisal lingkungan. Berdasarkan uraian di atas, hipotesis yang dapat dirumuskan dalam penelitian ini adalah.

$\mathrm{H}_{1}$ : Ukuran perusahaan berpengaruh positif pada nilai perusahaan.

Leverage merupakan perbandingan antara total utang terhadap total aset perusahaan. Leverage mengindikasikan persentase penggunaan dana dari pihak kreditur untuk membiayai aset perusahaan. Perusahaan yang memiliki tingkat leverage yang tinggi akan lebih berhati-hati di dalam mengambil tindakan yang menyangkut dengan pengeluaran-pengeluaran hal ini termasuk tindakan pencegahan dan juga pengurangan karbon (Suaidah, 2018). Hal ini terjadi dikarenakan keterbatasan alokasi dana yang dimiliki, perusahaan diharuskan memilih menggunakan dana tersebut untuk melunasi segala kewajiban atau untuk melakukan pengungkapan sukarela. Pembuatan laporan sukarela berarti akan menambah biaya lebih besar sehingga dapat menambah beban perusahaan (Lucyanda \& Siagian, 2012). Peneliti merumuskan hipotesis sebagai berikut.

$\mathrm{H}_{2}$ : Leverage perusahaan berpengaruh negatif pada nilai perusahaan.

Pengungkapan lingkungan mrupakan salah satu prinsip akuntansi yang dikenal dengan istilah full disclosure (pengungkapan penuh). Menurut prinsip akuntansi full disclosure, beberapa pengungkapan harus dilaporkan dalam pelaporan keuangan agar pelaporan kepada pihak eksternal tidak menyesatkan. Pengungkapan secara umum terbagi atas dua jenis, yaitu voluntary disclosure dan 
mandatory disclosure. Voluntary disclosure adalah pengungkapan berbagai informasi yang berkaitan dengan aktivitas perusahaan secara sukarela. Meski pada kenyataannya pengungkapan secara sukarela tidak benar-benar terjadi karena terdapat kecenderungan bagi perusahaan untuk menyimpan dengan sengaja informasi yang sifatnya dapat menurunkan arus kas (Wiguna \& Putri, 2016). Hal tersebut dianggap dapat menyebabkan kerugian pada perusahaan. Ghozali \& Chairiri, (2007) berpendapat bahwa perusahaan akan mengungkapkan semua informasi yang diperlukan dalam rangkan berjalannya fungsi pasar modal.

Environmental disclosure merupakan salah satu pengungapan sukarela yang merupakan bagoan dari pelaporan tanggung jawab jawab sosial perusahaan. Jika manfaat yang akan diperoleh dengan melakukan pengungkapan informasi tersebut lebih besar dibandingkan biaya yang dikeluarkan untuk mengungkapkannya maka perusahaan akan dengan sukarela mengungkapkan informasi tersebut dan sebaliknya (Reni \& Anggraini, 2006). Sulistiawati \& Dirgantari (2016) menyatakan bahwa pengungkapan lingkungan merupakan wujud pertanggungjawaban sosial perusahaan melalui penggungkapan lingkungan hidup pada laporan tahunan dimana masyarakat dapat memantau aktivitas yang dilakukan oleh perusahaan dalam memenuhi tanggung jawab sosialnya. Berdasarkan uraian tersebut, maka hipotesis yang dirumuskan sebagai berikut.

$\mathrm{H}_{3}$ : Pengungkapan lingkungan berpengaruh negatif pada nilai perusahaan.

Kinerja lingkungan berhubungan dengan seberapa baik perusahaan mengelola aspek lingkungan dari aktivitas, produk, jasa serta akibatnya terhadap lingkungan. Sejalan dengan teori legitimasi, jika kinerja lingkungan perusahaan baik maka opini publik terhadap perusahaan tersebut akan meningkat, begitu juga sebaliknya (Rakhiemah \& Agustia, 2011; Sudjana \& Sudana, 2017). Ketika opini publik terhadap perusahaan baik, maka posisi perusahaan di mata publik juga baik (Aulia \& Agustina, 2015).Oleh karena itu, perusahaan dengan environmental performance yang baik perlu mengungkapkan informasi kuantitas dan mutu lingkungan yang lebih baik dibandingkan perusahaan dengan environmental performance yang lebih buruk. Semakin banyak peran perusahaan dalam kegiatan lingkungannya, maka akan semakin banyak pula yang harus diungkapkan oleh perusahaan mengenai kinerja lingkungan yang dilakukannya dalam laporan tahunannya.

Hal ini akan mencerminkan transparansi dari perusahaan tersebut bahwa perusahaan juga berkepentingan dan bertanggung jawab terhadap apa yang telah dikerjakannya sehingga masyarakat juga akan tahu seberapa besar tanggung jawab dan andil perusahaan terhadap lingkungannya (Anom Purbawangsa et al., 2015) dan (Ciriyani \& Putra, 2016). Semakin baik kinerja lingkungan yang menggunakan pedoman indeks pengungkapan GRI V.4.0 maka perusahaan akan mengungkapkan lebih banyak informasi lingkungan dibandingkan dengan perusahaan dengan kinerja lingkungan yang buruk (Dewi \& Yasa, 2017). Berdasarkan uraian tersebut, maka hipotesis yang dirumuskan sebagai berikut.

$\mathrm{H}_{4}$ : Kinerja lingkungan berpengaruh negatif pada nilai perusahaan. 


\section{METODE PENELITIAN}

Penelitian tentang nilai perusahaan ini menggunakan pendekatan kuantitatif yang berbentuk asosiatif. BEI (Bursa Efek Indonesia) merupakan tepat dilakukannya penelitian ini. Ruang lingkup penelitian ini adalah perusahaan LQ45 yang teradftar di BEI. Objek penelitian dalam penelitian ini adalah ukuran perusahaan $\left(X_{1}\right)$, leverage $\left(X_{2}\right)$, pengungkapan lingkungan $\left(X_{3}\right)$, kinerja lingkungan $\left(\mathrm{X}_{4}\right)$, dan nilai perusahaan $(\mathrm{Y})$. Variabel dependen dalam penelitian ini adalah nilai perusahaan. Variabel independen dalam penelitian ini adalah ukuran perusahaan, leverage, pengungkapan lingkungan, dan kinerja lingkungan. Jenis data yang digunakan dalm penelitian ini adalah data kuantitatif yaitu laporan tahunan perusahaan yang terdaftar di BEI periode 2015-2018. Data dalam penelitian ini merupakan data sekunder, diperoleh dari laporan tahunan dari perusahaan yang memenuhi kriteria.

Pengukuran nilai perusahaan diukur dengan rasio pasar yaitu Tobin's Q. Rumus Tobin's Q adalah sebagai berikut.

Tobin's $Q=\frac{M S V+D}{T A}$

Keterangan :

MSV = Market value of all outstanding shares

$\mathrm{D} \quad=$ Debt

TA $=$ Total assets

Ukuran perusahaan diproksikan dengan menggunakan Log Natural Total Aset dengan tujuan agar mengurangi fluktuasi data yang berlebih. Maka ukuran perusahaan berdasarkan total aset dirumuskan sebagai berikut.

SIZE $=\operatorname{Ln}($ Total aset $)$

Rasio leverage berhubungan dengan keputusan pendanaan perusahaan yang lebih memilih pembiayaan utang dibanding modal sendiri 9aulia dan Agustina, 2015). Perhitungan leverage ini merujuk pada penelitian Akrout dan Othman (2016) dengan menggunakan rumus sebagai berikut.

Leverage $=$ Total liabilitas $/$ Total aset.

Pengungkapan lingkungan (environmental disclosure) merupakan pengungkapan lingkungan yang diukur dengan menggunakan metode skoring terhadap Indeks Pengungkapan Lingkungan (Environmental Disclosure Index) yang digunakan untuk mengukur sejauh mana pengungkapan lingkungan yang telah digunakan oleh perusahaan tahunan. Pengukuran environmental disclosure dapat diperoleh melalui pengungkapan CSR dalam annual reports maupun melalui sustainability report yang biasanya terpisah. Berdasarkan bidang lingkungan (environment), Indeks GRI G4 terdiri dari 1 dimensi dan 12 aspek. Dalam penelitian ini, pengukuran item environmental disclosure dilakukan dengan perhitungan skoring. Skor $0=$ Apabila perusahaan tidak mengungkapkan daftar item pada daftar pertanyaan indeks pengungkapan. Skor $1=$ Apabila perusahaan mengungkapkan daftar item pada daftar indeks pertanyaan indeks pengungkapan.

Setelah pengungkapan lingkungan dinilai berdasarkan daftar indeks pengungkapan lingkungan akan dihitung dengan metode menjumlahkan skor dari pengungkapan lingkungan yang dilakukan oleh perusahaan berdasarkan sumber pengungkapan dibagi dengan jumlah pengungkapan yang seharusnya 
dilakukan (Total pengungkapan lingkungan berdasarkan indeks pengungkapan lingkungan).

Skor akhir $=\frac{\text { Total pengungkapan lingkungan yang dilakukan }}{\text { Total pengungkapan lingkunganyang seharusnya dilakukan }}$

PROPER merupakan program dari Kementrian Lingkungan Hidup untuk menilai prestasi perusahaan dalam pengelolaan lingkungannya. PROPER menggunakan peringkat untuk menilai kinerja lingkungan perusahaan. Terdapat 5 (lima) kategori yang ditandai dengan warna-warna sebagai penanda peringkat.

Urutan peringkat dari yang terkecil hingga terbesar ialah hitam, merah, biru, hijau dan emas (Nugraha, 2015). Penilaian ini menggunakan data ordinal yaitu pengukuran kinerja dengan menggunakan skor 1 sampai 5 PROPER. Urutan skor peringkat tersebut yaitu Emas (Skor 5), Hijau (Skor 4), Biru (Skor 3), Merah (Skor 2) dan Hitam (Skor 1)dapat dilihat dalam Tabel 1 berikut.

Tabel 1. Peringkat PROPER

\begin{tabular}{ccc}
\hline Skala & Arti & Warna \\
\hline 1 & Sangat Buruk & Hitam \\
2 & Buruk & Merah \\
3 & Baik & Biru \\
4 & Sangat Baik & Hijau \\
5 & Sangat Baik Sekali & Emas \\
\hline
\end{tabular}

Sumber: Kementrian Lingkungan Hidup, 2015

\section{HASIL DAN PEMBAHASAN}

Statistik deskriptif dalam penelitian ini memberikan gambaran mengenai data yang tersaji seperti nilai minimum, nilai maksimum, nilai rata-rata (mean) dan standar deviasi.

\section{Tabel 2. Hasil Uji Normalitas Persamaan Regresi}

\begin{tabular}{lr}
\hline \multicolumn{1}{c}{ Unstandardized Residual } \\
\hline $\mathrm{N}$ & 32,000 \\
Kolmogorov-Smirnov Z & 0,096 \\
Asymp. Sig. (2-tailed) & $0,200^{\mathrm{c}, \mathrm{d}}$ \\
\hline
\end{tabular}

Sumber: Data Penelitian, 2020

Tabel 2, menunjukkan nilai Kolmogorov-Smirnov Zsebesar0,096 dan nilai Asymp. Sig. (2-tailed) sebesar 0,200. Residual berdistribusi normal apabila memiliki nilai signifikan lebih besar dari 0,05. Jadi, dapat disimpulkan bahwa model persamaan regresi tersebt berdistribusi normal.

Tabel 3. Hasil Uji Multikolinearitas Persamaan Regresi

\begin{tabular}{llrr}
\hline \multicolumn{1}{c}{ Model } & & $\begin{array}{c}\text { Collinearity } \\
\text { Statistics }\end{array}$ & Model \\
& & 0,269 & 3,718 \\
1 & (Constant) & 0,483 & 2,070 \\
& Ukuran_Perusahaan & 0,247 & 4,055 \\
& Leverage & 0,278 & 3,594 \\
\hline
\end{tabular}

Sumber: Data Penelitian, 2020

Tabel 3, menunjukkan nilai tolerance 0,269 pada ukuran perusahaan, 0,483 pada leverage, 0,247 pada pengungkapan lingkungan, dan 0,278 pada kinerja lingkungan. Selain itu, nilai VIF sebesar 3,718 pada Ukuran perusahaan, 2,070 pada leverage, 4,055 pada pengungkapan lingkungan, dan 3,594 pada kinerja 
lingkungan. Model regresi yang bebas dari gejala multikolinearitas adalah yang mempunyai nilai tolerance lebih besar dari 0,01 dan nilai VIF kurang dari 10. Jadi dapat disimpulkan model diatas bebas dari multikolinearitas.

Tabel 4. Hasil Uji Heterokedastisitas Persamaan Regresi

\begin{tabular}{|c|c|c|c|c|c|c|}
\hline \multirow[b]{2}{*}{ Model } & & \multicolumn{2}{|c|}{$\begin{array}{l}\text { Unstandardized } \\
\text { Coefficients }\end{array}$} & $\begin{array}{l}\text { Standardized } \\
\text { Coefficients }\end{array}$ & \multirow[b]{2}{*}{$t$} & \multirow[b]{2}{*}{ Sig. } \\
\hline & & B & Std. Error & Beta & & \\
\hline \multirow[t]{5}{*}{1} & (Constant) & 143,222 & 99,730 & & 1,436 & 0,162 \\
\hline & Ukuran & $-41,277$ & 28,836 & $-0,506$ & $-1,431$ & 0,164 \\
\hline & $\begin{array}{l}\text { Perusahaan } \\
\text { Leverage }\end{array}$ & $-0,107$ & 0,351 & $-0,104$ & $-0,305$ & 0,763 \\
\hline & Pengungkapan & $-0,923$ & 2,197 & $-0,164$ & $-0,420$ & 0,678 \\
\hline & $\begin{array}{l}\text { Kinerja } \\
\text { Lingkungan }\end{array}$ & $-3,608$ & 4,262 & $-0,314$ & $-0,846$ & 0,405 \\
\hline
\end{tabular}

Sumber: Data Penelitian, 2020

Berdasarkan Tabel 4, menunjukkan nilai sig. ukuran perusahaan adalah 0,164, leverage sebesar 0,763, pengungkapan lingkungan sebesar 0,678 dan kinerja lingkungan sebesar 0,405. Tingkat signifikansi tersebut lebih besar dari 0,05 . Sehingga dapat disimpulkan bahwa model persamaan bebas dari heteroskedastisitas.

\section{Tabel 5. Hasil Uji Autokorelasi Persamaan Regresi}

\begin{tabular}{lr}
\hline & \\
\hline Test Value & \\
Cases $<$ Test Value & $-0,098$ \\
Cases $>=$ Test Value & 16,000 \\
Total Cases & 16,000 \\
Number of Runs & 32,000 \\
Z & 12,000 \\
Asymp. Sig. (2-tailed) & $-1,617$ \\
\hline
\end{tabular}

Sumber: Data Penelitian, 2020

Tabel 5, menunjukkan Nilai Asymp. Sig. (2 tailed) lebih besar dari 0.05, maka tidak terdapat gejala autokorelasi.

Tabel 6. Hasil Analisis Regresi Linear Berganda

\begin{tabular}{|c|c|c|c|c|c|c|}
\hline \multirow[b]{2}{*}{ Model } & & \multicolumn{2}{|c|}{$\begin{array}{l}\text { Unstandardized } \\
\text { Coefficients }\end{array}$} & $\begin{array}{l}\text { Standardized } \\
\text { Coefficients }\end{array}$ & \multirow[b]{2}{*}{$\mathrm{t}$} & \multirow[b]{2}{*}{ Sig. } \\
\hline & & B & $\begin{array}{l}\text { Std. } \\
\text { Error }\end{array}$ & Beta & & \\
\hline 1 & (Constant) & 55,081 & 64,389 & & & \\
\hline & Ukuran Perusahaan & $-1,156$ & 1,764 & $-0,172$ & $-0,656$ & 0,518 \\
\hline & Leverage & 19,298 & 5,909 & 0,640 & 3,266 & 0,003 \\
\hline & $\begin{array}{l}\text { Pengungkapan } \\
\text { Lingkungan }\end{array}$ & $-15,774$ & 11,605 & $-0,373$ & $-1,359$ & 0,185 \\
\hline & Kinerja Lingkungan & $-4,482$ & 2,028 & $-0,571$ & $-2,211$ & 0,036 \\
\hline
\end{tabular}

Sumber: Data Penelitian, 2020

Berdasarkan Tabel 6, diperoleh nilai $\beta$ pada kolom Unstandardized Coefficients sebagai koefisisen regresi. Dengan demikian dapat dilihat persamaan regeresi sebagai berikut. 
Tabel 7. Hasil Uji F Model Regresi Linear Berganda

\begin{tabular}{lllllll}
\hline Model & & Sum of Squares & df & Mean Square & F & Sig. \\
\hline 1 & Regression & 579.364 & 4 & 144,841 & 6,709 & $0,001^{\mathrm{b}}$ \\
& Residual & 582.898 & 27 & 21,589 & & \\
& Total & 1162.262 & 31 & & & \\
\end{tabular}

Sumber: Data Penelitian, 2020

Berdasarkan Tabel 7, dapat diketahui nilai F sebesar 6,709 dengan tingkat signifikansi sebesar 0,001. Hasil tersebut lebih kecil dari nilai $\alpha=0,05$ $(0,001<0,05)$, maka dapat disimpulkan bahwa model ini layak digunakan dalam penelitian dan secara bersama-sama nilai perusahaan dapat dijelaskan oleh variabel kinerja lingkungan, leverage, ukuran perusahaan dan pengungkapan lingkungan.

Tabel 8. Hasil Koefisien Determinasi Model Regresi Linear Berganda

\begin{tabular}{lllll}
\hline Model & $\mathrm{R}$ & R Square & $\begin{array}{l}\text { Adjusted } R \\
\text { Square }\end{array}$ & $\begin{array}{l}\text { Std. Error of } \\
\text { the Estimate }\end{array}$ \\
\hline 1 & $0,706^{\mathrm{a}}$ & 0,498 & 0,424 & 4,64637621 \\
\hline
\end{tabular}

Sumber: Data Penelitian, 2020

Berdasarkan Tabel 8, diketahui bahwa $R$ Square adalah sebesar 0,498. Hal ini berarti bahwa 49,8\% variasi nilai perusahaan dapat dejelaskan oleh variabel kinerja lingkungan, leverage, ukuran perusahaan dan,pengungkapanlingkungan sedangkan $50,2 \%$ nilai perusahaan dijelaskan oleh variabel lain yang tidak dimasukan ke dalam model penelitian.

Nilai koefisien korelasi (R) adalah sebesar 0,706 menunjukkan bahwa koefisien korelasi sebesar 70,6\%. Dari nilai ini dapat disimpulkan bahwa hubungan antara kinerja lingkungan, leverage, ukuran perusahaan dan,pengungkapanlingkungan dengan nilaiperusahaanmemiliki posisi yang cukup kuat.

Tabel 9. Hasil Uji t Model Regresi Linear Berganda

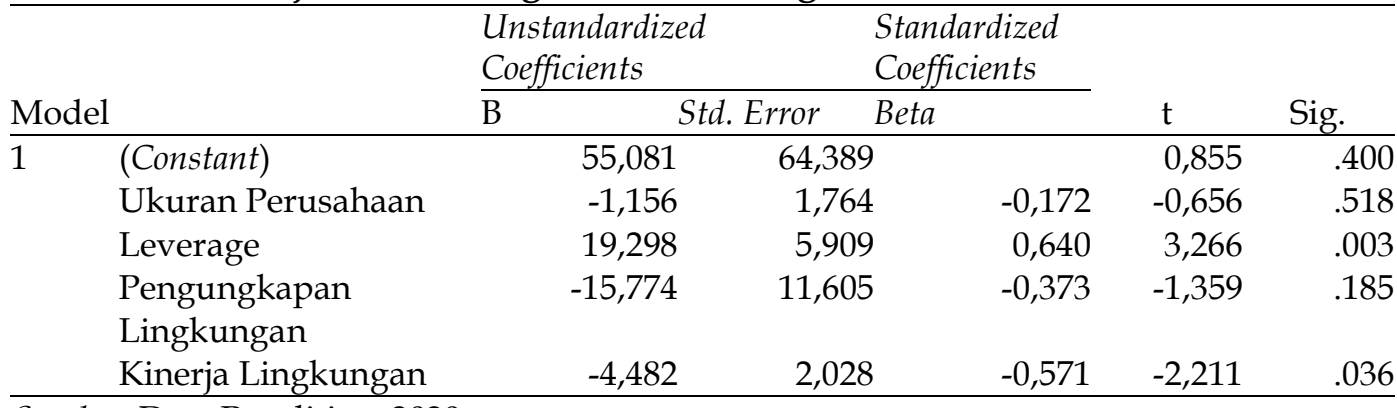

Sumber: Data Penelitian, 2020

Dapat dilihat dari Tabel 9, sehingga hasil pengujian hipotesis dapat dijelaskan sebagai berikut. Dapat dilihat nilai signifikansi $x_{1}$ Ukuran Perusahaan sebesar 0,518 lebih besar dari nilai $p$ yang ditentukan 0,05, atau 0,518>0,05 maka dapat dikatakan bahwa tidak terdapat pengaruh variable ukuran perusahaan terhadap variable nilai perusahaan. Dapat dilihat nilai signifikansi $x_{2}$ Leverage sebesar 0,003 lebih kecil dari nilai p yang ditentukan 0,05, atau 0,003 $<0,05$ maka dapat dikatakan bahwa terdapat pengaruh variable $x_{2}$ Leverage terhadap variable nilai perusahaan. Dapat dilihat nilai signifikansi $x_{3}$ Pengungkapan Lingkungan sebesar 0,185 lebih besar dari nilai $\mathrm{p}$ yang ditentukan 0,05, atau 0,185>0,05 maka dapat dikatakan bahwa tidak terdapat pengaruh variable $x_{3}$ Pengungkapan 
Lingkungan terhadap variable nilai perusahaan. Dapat dilihat nilai signifikansi $x_{4}$ Kinerja Lingkungan sebesar 0,036 lebih kecil dari nilai p yang ditentukan 0,05, atau $0,036<0,05$ maka dapat dikatakan bahwa terdapat pengaruh variable $x_{4}$ Kinerja Lingkungan terhadap variable nilai perusahaan.

\section{SIMPULAN}

Simpulan yang dapat ditarik berdasarkan hasil dan pembahasan yang sudah dijelaskan sebelumnya yaitu ukuran perusahaan berpengaruh negatif dantidak signifikan terhadap nilaiperusahaan. Hal ini berarti besar atau kecilnya perusahaan tidak mempengaruhi nilai perusahaan. Leverage berpengaruh positif dan signifikan terhadap nilai perusahaan. Hal ini berarti besar atau kecilnya kewajiban yang dimiliki oleh perusahaan mempengaruhi nilai perusahaan. Pengungkapan lingkungan berpengaruh negatif dan tidak signifikan terhadap nilai perusahaan. Kinerja lingkungan berpengaruh psitif dan signifikan terhadap nilai perusahaan. Hal ini berarti bahwa semakin baik kinerja lingkungan yang dicapai oleh perusahaan maka semakin tinggi nilai perusahaan tersebut.

\section{REFERENSI}

Adiatma, K. B., \& Suryanawa, I. K. (2018). Pengaruh Tipe Industri, Kepemilikan Saham Pemerintah, Profitabilitas Terhadap Sustainability Report. E-Jurnal Akuntansi, 25(2), 934-958. https://doi.org/10.24843/eja.2018.v25.i02.p05

Ahmadi, A., \& Bouri, A. (2017). The relationship between financial attributes, environmental performance and environmental disclosure: Empirical investigation on French firms listed on CAC 40. Management of Environmental Quality: An International Journal, 28(4), 490-506. https:/ / doi.org/10.1108/MEQ-07-2015-0132

Anom Purbawangsa, I. B., Wiagustini, N. L. P., \& Agus Dwipayadnya, P. (2015). Kepemilikan Manajerial dan Leverage sebagai Prediktor Profitabilitas dan Pengungkapan Corporate Social Responsibility. Buletin Studi Ekonomi, 20(2), 83-176.

Aulia, F. Z., \& Agustina, L. (2015). Pengaruh Karakteristik Perusahaan, Kinerja Lingkungan, Dan Liputan Media Terhadap Environmental Disclosure. Accounting Analysis Journal, 4(3). https://doi.org/10.15294/aaj.v4i3.8306

Ciriyani, N., \& Putra, I. (2016). Pengaruh Ukuran Perusahaan, Profitabilitas, Dan Umur Perusahaan Pada Pengungkapan Informasi Lingkungan. E-Jurnal Akuntansi, 17(3), 2091-2119.

Damayanthi, I. G. A. E. (2019). Fenomena Faktor yang Mempengaruhi Nilai Perusahaan. Jurnal Ilmiah Akuntansi Dan Bisnis, 14(2), 208-218. https:// doi.org/10.24843/JIAB.2019.v14.i02.p06

Dewi, Y., \& Yasa, G. W. (2017). Pengaruh Ukuran Perusahaan, Profitabilitas, Tipe Industri Dan Kinerja Lingkungan Terhadap Environmental Disclosure. EJurnal Akuntansi, 20(3), 2362-2391.

Freeman, R. E., Harrison, J. S., Wicks, A. C., Parmar, B., \& de Colle, S. (2010). Stakeholder theory: The state of the art. In Stakeholder Theory: The State of the Art. https://doi.org/10.1017/CBO9780511815768

Ghozali, I., \& Chairiri, A. (2007). Teori Akuntansi. Universitas Diponegoro.

He, W., \& Luo, J. (2018). Agency problems in firms with an even number of 
directors: Evidence from China. Journal of Banking \& Finance, 93, 139-150.

Kori, M. O. D., \& Rasmini, N. K. (2017). Struktur Good Corporate Governance sebagai Pemoderasi Pengaruh Asimetri Informasi pada Manajemen Laba. EJurnal Akuntansi Universitas Udayana, 21(1), 144-172.

Lindawati, A. S. L., \& Puspita, M. E. (2015). Corporate Social Responsibility: Implikasi Stakeholder dan Legitimacy Gap dalam Peningkatan Kinerja Perusahaan. Jurnal Akuntansi Multiparadigma, 6(1), 157-174.

Lu, J., \& Wang, H. (2020). Institutional Knowledge at Singapore Management University Geographic influences on the relationship between corporate philanthropy and corporate financial performance. Geographical in fl uences on the relationship between corporate philanthropy and corp. 660-676.

Lucyanda, J., \& Siagian, L. G. (2012). The Influence of Company Characteristics Toward Corporate Social Responsibility Disclosure. The 2012 International Conference on Business and Management.

Nugraha, D. E. B. (2015). Profitabilitas, Leverage, dan Kinerja Lingkungan terhadap Environmental Disclosure. Jurnal Ilmiah Akuntansi Dan Bisnis Universitas Diponegoro.

Prameswari, A. S., \& Yustrianthe, R. H. (2017). Analisis Faktor - Faktor Yang Memengaruhi Audit Delay (Studi Empiris Pada Perusahaan Manufaktur Yang Terdaftar Di Bursa Efek Indonesia). Jurnal Akuntansi. https://doi.org/10.24912/ja.v19i1.113

Rakhiemah, A. N., \& Agustia, D. (2011). Pengaruh Kinerja Lingkungan Terhadap Corporate Social Responsibility (CSR) Disclosure Dan Kinerja Financial Perusahaan Manufaktur Yang Terdaftar Di Bursa Efek Indonesia. Simposium Nasional Akuntansi 12 : Palembang, 1-31.

Reni, F., \& Anggraini, R. (2006). Pengungkapan Informasi Sosial dan FaktorFaktor yang Mempengaruhi Pengungkapan Informasi Sosial dalam Laporan Keuangan Tahunan ( Studi Empiris pada Perusahaan-Perusahaan yang terdaftar Bursa Efek Jakarta ). Simposium Nasional Akuntansi 9 Padang, 23-26.

Ross, S. A. (1977). Determination Of Financial Structure: The Incentive-Signalling Approach. Bell J Econ. https:// doi.org/10.2307/3003485

Sabatini, K., \& Sudana, I. P. (2019). Pengaruh Pengungkapan Corporate Social Responsibility Pada Nilai Perusahaan Dengan Manajemen Laba Sebagai Variabel Moderasi. Jurnal Ilmiah Akuntansi Dan Bisnis, 14(1), 56-69. https:// doi.org/10.24843/jiab.2019.v14.i01.p06

Santoso, A. D., Utomo, S. W., \& Astuti, E. (2017). Pengaruh kepemilikan saham publik, ukuran perusahaan dan profitabilitas terhadap corporate social responsibility disclosure (studi pada perusahaan perbankan yang terdaftar di bei periode 2012-2015. Forum Ilmiah Pendidikan Akuntansi, 9(1), 836-854.

Singh, R. R., Chauhan, A., Agrawal, S., \& Kapoor, S. (2011). Analisis Pengaruh Iklim Kerja Dan Pengembangan Karir Terhadap Komitmen Karir Dengan Kepuasan Kerja Sebagai Variabel Intervening. IJCSMS International Journal of Computer Science and Management Studies, 11(2), 9-18.

Suaidah, Y. M. (2018). Pengaruh Pengungkapan Akuntansi Lingkungan dan Kepemilikan Saham Terhadap Nilai Perusahaan Melalui Kinerja Keuangan. Jurnal Riset Akuntansi Dan Keuangan Dewantara, 1(2), 105-116.

Sudjana, N. L. A. S., \& Sudana, I. P. (2017). Faktor-Faktor Yang Mempengaruhi 
Pengungkapan CSR Dengan Profile Perusahaan Sebagai Variabel Pemoderasi. E-Jurnal Akuntansi Universitas Udayana, 19(3), 2468-2495.

Sulistiawati, E., \& Dirgantari, N. (2016). Analisis Pengaruh Penerapan Green Accounting Terhadap Profitabilitas Pada Perusahaan Pertambangan Yang Terdaftar Di Bursa Efek Indonesia. Jurnal Reviu Akuntansi Dan Keuangan, 6(1), 865-872.

Wiguna, I. P., \& Putri, I. G. A. M. A. D. (2016). Voluntary Disclosure Sebagai Pemoderasi Pengaruh Good Corporate Governance Terhadap Nilai Perusahaan. E-Jurnal Akuntansi, 17(3), 1700-1726.

Wijayanti, A., Wijayanti, A., \& Samrotun, Y. C. (2016). Pengaruh Karakteristik Perusahaan, GCG dan CSR Terhadap Penghindaran Pajak. Seminar Nasional IENACO -.

Yanti, N. K. A. G., \& Budiasih, I. G. A. N. (2016). Pengaruh Profitabilitas, Leverage Dan Ukuran Perusahaan Pada Pengungkapan Corporate Social Responsibility. E-Jurnal Akuntansi Universitas Udayana, 17(3), 1752-1779. 